(A) Check for updates

Cite this: Polym. Chem., 2021, 12, 5760

Received 27th July 2021,

Accepted 20th September 2021

DOI: $10.1039 / \mathrm{d} 1$ py01008e

rsc.li/polymers

\section{RAFT aqueous emulsion polymerization of methyl methacrylate: observation of unexpected constraints when employing a non-ionic steric stabilizer block $\uparrow$}

\author{
Derek H. H. Chan, ${ }^{a}$ Amy A. Cockram, ${ }^{a}$ Rebecca R. Gibson, ${ }^{a}$ Emily L. Kynaston, ${ }^{b}$ \\ Christopher Lindsay, ${ }^{\mathrm{b}}$ Philip Taylor ${ }^{\mathrm{b}}$ and Steven P. Armes (D) *a
}

The RAFT aqueous emulsion polymerization of methyl methacrylate (MMA) is conducted at $70{ }^{\circ} \mathrm{C}$ using poly(glycerol monomethacrylate) (PGMA) as a steric stabilizer block. This non-ionic precursor has previously proved to be highly effective for the RAFT aqueous emulsion polymerization of various vinyl monomers such as benzyl methacrylate (BzMA), 2,2,2-trifluoroethyl methacrylate (TFEMA), isopropylideneglycerol monomethacrylate (IPGMA) or glycidyl methacrylate. However, an unexpected constraint was encountered in the case of MMA. Targeting a degree of polymerization (DP) of 20 to 100 for the PMMA block led to colloidal dispersions of kinetically-trapped spherical nanoparticles ranging in size from $17 \mathrm{~nm}$ to $31 \mathrm{~nm}$. On the other hand, targeting DPs above 100 invariably led to the formation of highly flocculated spherical nanoparticles. This rather limited DP range is in striking contrast to the much higher DPs that can be targeted without loss of colloidal stability when using more hydrophobic monomers such as BzMA, TFEMA or IPGMA. The same flocculation problem was also evident when employing a PGMA precursor containing an anionic carboxylate end-group, but a series of colloidally stable dispersions could be obtained when using an anionic poly(methacrylic acid) stabilizer. Finally, the efficient removal of RAFT end-groups from PGMA ${ }_{50}{ }^{-}$ $\mathrm{PMMA}_{80}$ nanoparticles was achieved by visible light irradiation using a blue LED source $(\lambda=405 \mathrm{~nm})$. UV GPC studies confirmed that up to $87 \%$ dithiobenzoate end-groups can be removed from such nanoparticles within $12 \mathrm{~h}$ at $80{ }^{\circ} \mathrm{C}$. On the other hand, using excess $\mathrm{H}_{2} \mathrm{O}_{2}$ under the same conditions only led to $24 \%$ end-group removal. This is because this water-soluble reagent has restricted access to the hydrophobic PMMA cores.

\section{Introduction}

Reversible addition-fragmentation chain transfer (RAFT) polymerization is a well-established pseudo-living technique based on the principle of rapid reversible chain transfer that

\footnotetext{
${ }^{a}$ Dainton Building, Department of Chemistry, University of Sheffield, Brook Hill, Sheffield, South Yorkshire, S3 7HF, UK. E-mail: s.p.armes@sheffield.ac.uk

${ }^{b}$ Syngenta, Jealott's Hill International Research Centre, Bracknell, BerkshireRG42 $6 E Y, U K$

$\dagger$ Electronic supplementary information (ESI) available: Summary of GPC, DLS and TEM data obtained for HOOC-PGMA ${ }_{54}-$ PMMA $_{80}$ nanoparticles and HOOC-PGMA ${ }_{54}-\mathrm{PMMA}_{150}$ nanoparticles synthesised with PETTC RAFT agent; synthesis of the PMETAC 46 precursor and the corresponding PMETAC $_{46}-\mathrm{PMMA}_{x}$ nanoparticles; DLS and TEM data obtained for PMETAC 46 -PMMA ${ }_{x}$ nanoparticles; UV GPC curves $(\lambda=309 \mathrm{~nm})$ recorded during kinetic studies of the removal of dithiobenzoate end-groups from an aqueous dispersion of $\mathrm{PGMA}_{50}-\mathrm{PMMA}_{80}$ nanoparticles using either excess $\mathrm{H}_{2} \mathrm{O}_{2}$ or no light irradiation at $80{ }^{\circ} \mathrm{C}$. UV GPC curves $(\lambda=309 \mathrm{~nm})$ recorded during the removal of trithiocarbonate end-groups from an aqueous dispersion of HOOC-PGMA ${ }_{54}-\mathrm{PMMA}_{80}$ nanoparticles using visible light irradiation, excess $\mathrm{H}_{2} \mathrm{O}_{2}$ or neither condition at $80{ }^{\circ} \mathrm{C}$. See DOI: 10.1039/d1py01008e
}

enables the convenient synthesis of a wide range of controlled-structure vinyl polymers using various organosulfurbased reagents. ${ }^{1-5}$ RAFT polymerization is exceptionally tolerant of monomer functionality and is usually conducted in either organic solvents or aqueous solution to afford soluble polymer chains. ${ }^{6}$ However, it is equally well-suited to heterogeneous conditions such as suspension, ${ }^{7}$ dispersion $^{8-12}$ or emulsion $^{13-15}$ polymerization. In particular, RAFT aqueous emulsion polymerization - which is an important example of polymerization-induced self-assembly (PISA) ${ }^{16,17}$ - enables the controlled polymerization of a wide range of waterimmiscible vinyl monomers in aqueous media. ${ }^{17-19}$ Typically, spherical nanoparticles of tunable particle size can be readily prepared at high solids, ${ }^{16}$ although so-called 'higher order' copolymer morphologies (e.g. worms or vesicles) are also accessible for at least some formulations. ${ }^{18-20}$ Potential applications for such nano-objects include surface modifiers for cellulose fibres, ${ }^{21}$ viscosity modifiers, ${ }^{22}$ organic opacifiers for paints ${ }^{23}$ and additives for the reinforcement of latex films. ${ }^{24}$ 
There are many reports of the RAFT aqueous emulsion polymerization of commodity monomers such as styrene, ${ }^{12,23,25-27} n$-butyl acrylate ${ }^{13,28-30}$ or vinyl acetate. ${ }^{31}$ Moreover, there are also various reports of the use of speciality vinyl monomers such as benzyl methacrylate, ${ }^{32}$ 2,2,2-trifluoroethyl methacrylate, ${ }^{33}$ isopropylideneglycerol monomethacrylate, ${ }^{34}$ 2-methoxyethyl methacrylate, ${ }^{35}$ glycidyl methacrylate, ${ }^{36-39}$ or hydroxybutyl methacrylate. ${ }^{40}$ However, given its undoubted importance as a commodity monomer, there are surprisingly few literature reports of the RAFT aqueous emulsion polymerization of methyl methacrylate (MMA). ${ }^{21,29,41-43}$ Moreover, given the moderately high aqueous solubility of this monomer $\left(15.9 \mathrm{~g} \mathrm{dm}^{-3}\right.$ at $\left.20^{\circ} \mathrm{C}\right)$, such PISA formulations might be expected to provide convenient access to a wide range of block copolymer nano-objects (e.g. spheres, worms and vesicles). ${ }^{35,39,40,44}$

In the present study, we examine the RAFT emulsion polymerization of MMA using poly(glycerol monomethacrylate) (PGMA) as a water-soluble precursor (Scheme 1), which is known to act as an effective non-ionic steric stabilizer for various other water-immiscible vinyl monomers under such conditions. $^{32-36}$ In view of the unexpected limited utility of this PISA formulation, a PGMA stabilizer containing an anionic carboxylate end-group and an anionic poly(methacrylic acid) stabilizer were also evaluated for the RAFT emulsion polymerization of MMA.

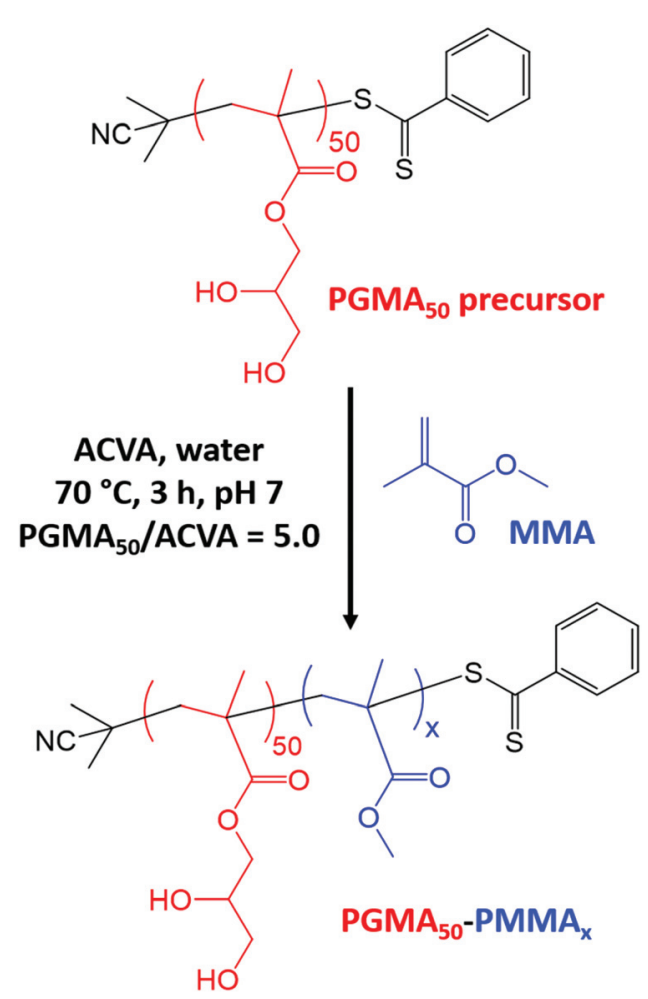

Scheme 1 Synthesis of $\mathrm{PGMA}_{50}-\mathrm{PMMA}_{x}$ diblock copolymer nanoparticles by RAFT aqueous emulsion polymerization of methyl methacrylate MMA at $70{ }^{\circ} \mathrm{C}$ using a dithiobenzoate-capped PGMA ${ }_{50}$ precursor to target $x=20$ to 130 at $\mathrm{pH} 7$.

\section{Experimental section}

\section{Materials}

Glycerol monomethacrylate (GMA) was donated by GEO Specialty Chemicals (Hythe, UK). Methyl methacrylate (MMA; 99\%), 4,4'-azobis(4-cyanopentanoic acid) (ACVA; 98\%), methacrylic acid (MAA; 99\%), [2-(methacryloyloxy)ethyl]tri methylammonium chloride (METAC; 80\% solution), 2-cyano-2propyl benzodithioate (CPDB; 97\%) and trimethylsilyl diazomethane solution $(2.0 \mathrm{M}$ in hexanes) were each purchased from Sigma-Aldrich (UK) and used as received. 4-Cyano-4-(2phenylethanesulfanylthiocarbonyl) sulfanylpentanoic acid (PETTC) was prepared according to a literature protocol. ${ }^{45}$ Deionized water from an Elga Medica DV25 water purification unit was used in all the experiments.

\section{Synthesis of the PGMA Fo $_{5}$ precursor by RAFT aqueous solution polymerization}

GMA monomer (30.0 g, $187 \mathrm{mmol})$, CPDB RAFT agent (0.589 g, 2.66 mmol; target PGMA DP = 70) and ACVA initiator $(0.149 \mathrm{~g}, 0.53 \mathrm{mmol}$; $\mathrm{CPDB} / \mathrm{ACVA}$ molar ratio $=5.0)$ were weighed into a $250 \mathrm{~mL}$ round-bottom flask. Ethanol (46.5 g, $60 \% \mathrm{w} / \mathrm{w}$ ) was added and the flask was cooled by immersing in an ice bath while degassed with $\mathrm{N}_{2}$ gas for $30 \mathrm{~min}$. The flask was then immersed in an oil bath at $70{ }^{\circ} \mathrm{C}$ for $165 \mathrm{~min}$. The polymerization was quenched by exposing the reaction mixture to air and cooling the flask to $20{ }^{\circ} \mathrm{C}$. ${ }^{1} \mathrm{H}$ NMR spectroscopy indicated a final GMA conversion of $71 \%$. The reaction solution was diluted with methanol $(30 \mathrm{~mL})$ and then precipitated into a ten-fold excess of dichloromethane (three times). End-group analysis via ${ }^{1} \mathrm{H}$ NMR spectroscopy indicated a mean degree of polymerization (DP) of 50 (the integrated aromatic proton signals at 7.4-7.8 ppm were compared to the integrated methacrylic backbone proton signals at $0.7-2.5 \mathrm{ppm})$.

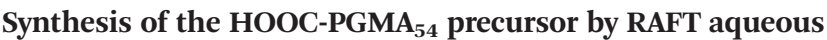 solution polymerization}

GMA monomer (10.0 g, $62.4 \mathrm{mmol})$, PETTC RAFT agent (0.302 g, $0.892 \mathrm{mmol}$; target PGMA DP $=70)$ and ACVA initiator $(0.050 \mathrm{~g}, 0.18 \mathrm{mmol}$; PETTC/ACVA molar ratio $=5.0)$ were weighed into a $100 \mathrm{~mL}$ round-bottom flask. Ethanol (15.5 g, $60 \% \mathrm{w} / \mathrm{w}$ ) was added and the flask was cooled by immersing in an ice bath while degassed with $\mathrm{N}_{2}$ gas for $30 \mathrm{~min}$. The flask was then immersed in an oil bath at $70{ }^{\circ} \mathrm{C}$ for $120 \mathrm{~min}$. The polymerization was quenched by exposing the reaction mixture to air and cooling the flask to $20{ }^{\circ} \mathrm{C}$. ${ }^{1} \mathrm{H}$ NMR spectroscopy indicated a final GMA conversion of $77 \%$. The solution was diluted with methanol $(10 \mathrm{~mL})$ and then precipitated into a ten-fold excess of dichloromethane (three times). End-group analysis via ${ }^{1} \mathrm{H}$ NMR spectroscopy indicated a mean DP of 54 .

Synthesis of PGMA Po-PMMA $_{x}$ diblock copolymer nanoparticles by RAFT aqueous emulsion polymerization

A typical protocol for the synthesis of $\mathrm{PGMA}_{50}-\mathrm{PMMA}_{x}$ diblock copolymer nanoparticles was as follows. PGMA $\mathrm{P}_{50}$ precursor 
(0.150 g, $18.2 \mu \mathrm{mol})$, MMA monomer (0.146 g, $1.46 \mathrm{mmol}$, target $\mathrm{DP}=80)$, ACVA initiator $\left(1.00 \mathrm{mg}, 3.65 \mu \mathrm{mol}, \mathrm{PGMA}_{50} / \mathrm{ACVA}\right.$ molar ratio $=5.0)$ and deionized water $(2.675 \mathrm{~g}, 10 \% \mathrm{w} / \mathrm{w}$ solution $)$ were added to a $20 \mathrm{~mL}$ round-bottom flask. The mixture was adjusted to $\mathrm{pH} 7$ using $1 \mathrm{M} \mathrm{NaOH}$. The flask was then placed in an ice bath and degassed with $\mathrm{N}_{2}$ gas for $30 \mathrm{~min}$, before immersing the flask in an oil bath set at $70{ }^{\circ} \mathrm{C}$. After $3 \mathrm{~h}$, the polymerization was quenched by exposing the reaction mixture to air while cooling the flask to $20^{\circ} \mathrm{C}$. Essentially the same protocol was employed for the synthesis of HOOC-PGMA ${ }_{54}-\mathrm{PMMA}_{x}$ diblock copolymer nanoparticles but in this case the HOOC-PGMA ${ }_{54}$ precursor was used instead of the $\mathrm{PGMA}_{50}$ precursor.

\section{Synthesis of the PMAA $_{56}$ precursor by RAFT aqueous solution polymerization}

MAA monomer (45.0 g, $0.523 \mathrm{~mol}$ ), PETTC RAFT agent (3.165 g, $9.34 \mathrm{mmol}$; target $\mathrm{DP}=56)$ and ACVA initiator $(0.523 \mathrm{~g}$, $1.87 \mathrm{mmol}$; PETTC/ACVA molar ratio $=5.0)$ and ethanol $(73.0 \mathrm{~g}$, $40 \% \mathrm{w} / \mathrm{w}$ ) were weighed into a $500 \mathrm{~mL}$ round-bottom flask. The solution was placed in an ice bath and degassed with $\mathrm{N}_{2}$ gas for $30 \mathrm{~min}$, before the flask was immersed in an oil bath at $70{ }^{\circ} \mathrm{C}$. The polymerization was quenched after $3 \mathrm{~h}$ by exposing the reaction mixture to air while cooling the flask to $20{ }^{\circ} \mathrm{C}$. The crude polymer was then precipitated into a ten-fold excess of diethyl ether. The insoluble polymer was redissolved in ethanol prior to a second precipitation step and then freeze-dried overnight. End-group analysis by ${ }^{1} \mathrm{H}$ NMR spectroscopy indicated a DP of 56 for this PMAA precursor.

\section{Synthesis of PMAA $_{56}-$ PMMA $_{x}$ diblock copolymer nanoparticles by RAFT aqueous emulsion polymerization}

A typical protocol for the synthesis of PMAA $_{56}-\mathrm{PMMA}_{100}$ diblock copolymer nanoparticles was conducted as follows. PMAA $_{56}$ precursor $(0.100 \mathrm{~g}, 19.4 \mu \mathrm{mol})$, MMA monomer (0.194 g, $1.94 \mathrm{mmol}$, target DP = 100), ACVA initiator $(1.10 \mathrm{mg}$, $3.88 \mu \mathrm{mol}, \mathrm{PMAA}_{56} / \mathrm{ACVA}$ molar ratio $\left.=5.0\right)$ and deionized water $(1.18 \mathrm{~g}, 20 \% \mathrm{w} / \mathrm{w}$ solution) were added to a $20 \mathrm{~mL}$ roundbottom flask. The mixture was adjusted to pH 5 using $1 \mathrm{M}$ $\mathrm{HCl}$. The reaction mixture was then placed in an ice bath and degassed with $\mathrm{N}_{2}$ gas for $30 \mathrm{~min}$, before immersing in an oil bath set at $70{ }^{\circ} \mathrm{C}$. The polymerization was allowed to proceed at this temperature for $6 \mathrm{~h}$ and then quenched by exposing the reaction mixture to air while cooling the flask to $20^{\circ} \mathrm{C}$.

\section{Methylation of PMAA $_{56}$-PMMA $x$ diblock copolymer nanoparticles}

Methylation of the carboxylic acid groups on the PMAA block was performed before THF GPC analysis. $\mathrm{PMAA}_{56}-\mathrm{PMMA}_{x}$ diblock copolymer powder $(20 \mathrm{mg})$ was diluted in THF $(2.0 \mathrm{~mL})$. Excess trimethylsilyldiazomethane was then gradually added to this solution until it turned yellow. The reaction mixture was stirred overnight, dried and analysed by THF GPC.

\section{Protocols for cleavage of RAFT end-groups}

The dithiobenzoate end-groups within $\mathrm{PGMA}_{50}-\mathrm{PMMA}_{80}$ nanoparticles were cleaved using the following protocol. A $10 \% \mathrm{w} / \mathrm{w}$ copolymer dispersion $(1.00 \mathrm{~g})$ was placed in a water-jacketed Schlenk tube wrapped in blue LED light strips $(\lambda=405 \mathrm{~nm}$, $0.37 \mathrm{~mW} \mathrm{~cm}^{-2}$ ) with the temperature of the water within the recirculating jacket set to $80{ }^{\circ} \mathrm{C}$. Aliquots of this reaction mixture were extracted periodically and analyzed using UV GPC (with the UV detector set at $\lambda=308 \mathrm{~nm}$ ). As a control experiment, the same protocol was used but without the blue LED light strips (i.e. no visible light irradiation). The same $10 \% \mathrm{w} / \mathrm{w}$ dispersion of $\mathrm{PGMA}_{50}-\mathrm{PMMA}_{80}$ nanoparticles was also treated with $\mathrm{H}_{2} \mathrm{O}_{2}$ (using a five-fold excess relative to the concentration of dithiobenzoate end-groups, as reported by Jesson and coworkers ${ }^{46}$ ) at $80{ }^{\circ} \mathrm{C}$ with no visible light irradiation. The same protocol was used for cleaving trithiocarbonate RAFT endgroups from a $10 \% \mathrm{w} / \mathrm{w}$ aqueous dispersion of $\mathrm{PGMA}_{54}-\mathrm{PMMA}_{80}$ nanoparticles. This included cleavage at $80{ }^{\circ} \mathrm{C}$ using blue LED strips, $\mathrm{H}_{2} \mathrm{O}_{2}$ or no visible light irradiation for $24 \mathrm{~h}$.

\section{Dynamic light scattering and aqueous electrophoresis}

DLS and aqueous electrophoresis studies were conducted on $0.50 \% \mathrm{w} / \mathrm{w}$ aqueous dispersions using a Malvern Zetasizer NanoZS instrument. The hydrodynamic $z$-average diameter was determined at $20^{\circ} \mathrm{C}$ at a scattering angle of $173^{\circ}$ and averaged over three measurements. Aqueous electrophoresis studies were conducted in the presence of $1 \mathrm{mM} \mathrm{KCl}$ as background electrolyte. The solution $\mathrm{pH}$ was adjusted using either $\mathrm{NaOH}$ or $\mathrm{HCl}$. Zeta potentials (also averaged over three measurements) were calculated via the Henry equation using the Smoluchowski approximation.

\section{Gel permeation chromatography (GPC)}

Molecular weight distributions of the PGMA 50 and HOOCPGMA $_{54}$ precursors and a series of $\mathrm{PGMA}_{50}-\mathrm{PMMA}_{80}$ diblock copolymers were assessed using DMF eluent (containing $10 \mathrm{mM} \mathrm{LiBr}$ ) at $60^{\circ} \mathrm{C}$. Two Polymer Laboratories PL gel $5 \mu \mathrm{m}$ Mixed-C columns were connected in series to a Varian 290-LC pump injection module and a Varian 390-LC multidetector suite (refractive index detector) at a flow rate of $1.0 \mathrm{~mL} \mathrm{~min}{ }^{-1}$. Near-monodisperse poly(methyl methacrylate) standards with $M_{\mathrm{p}}$ values ranging from $645 \mathrm{~g} \mathrm{~mol}^{-1}$ to $618000 \mathrm{~g} \mathrm{~mol}^{-1}$ were used for calibration. Molecular weights distributions of methylated $\mathrm{PMAA}_{56}-\mathrm{PMMA}_{x}$ diblock copolymers were assessed using THF eluent (containing $0.05 \% \mathrm{w} / \mathrm{v}$ butylhydroxytoluene and $2.0 \% \mathrm{v} / \mathrm{v}$ trimethylamine). Two Polymer Laboratories PL gel $5 \mu \mathrm{m}$ Mixed-C columns were connected in series to a WellChrom K-2301 refractive index detector at a flow rate of $1.0 \mathrm{~mL} \mathrm{~min}^{-1}$. Near-monodisperse poly(methyl methacrylate) standards were used for calibration.

\section{Transmission electron microscopy (TEM)}

Copper/palladium TEM grids (Agar Scientific, UK) were coated with a thin film of amorphous carbon. Grids were treated with a plasma glow discharge for $30 \mathrm{~s}$ to produce a hydrophilic surface. A $10 \mu \mathrm{L}$ droplet of a $0.10 \% \mathrm{w} / \mathrm{w}$ aqueous dispersion was placed on a grid and left for $1 \mathrm{~min}$ before blotting. The adsorbed nanoparticles were then stained using uranyl formate $(9.0 \mu \mathrm{L}$ of a $0.75 \% \mathrm{w} / \mathrm{w}$ aqueous solution) for $20 \mathrm{~s}$ fol- 
lowed by blotting to remove excess stain. Grids were carefully dried under vacuum and images were recorded at $100 \mathrm{kV}$ using a Philips CM100 instrument equipped with a Gatan 1k CCD camera.

\section{Small-angle X-ray scattering (SAXS)}

SAXS patterns were collected using a Xeuss 2.0 (Xenocs) SAXS instrument equipped with a Dectris Pilatus $1 \mathrm{M}$ detector and an Excillum liquid gallium MetalJet X-ray source $(\lambda=1.34 \AA)$. SAXS patterns were recorded for $1.0 \% \mathrm{w} / \mathrm{w}$ aqueous dispersions of $\mathrm{PGMA}_{50}-\mathrm{PMMA}_{x}$ nanoparticles over a scattering vector $q$ range of $0.04-0.4 \AA^{-1}$ using $2.0 \mathrm{~mm}$ diameter glass capillary cells. The scattering of deionized water was used for absolute intensity calibration. Irena SAS macros for Igor Pro software were used to perform background subtraction, normalization and data analysis. ${ }^{47}$

\section{Results and discussion}

\section{RAFT aqueous emulsion polymerization of MMA}

A PGMA precursor was prepared by RAFT solution polymerization of GMA in ethanol using a dithiobenzoate-based RAFT agent (CPDB) at $70{ }^{\circ} \mathrm{C}$. End-group analysis by ${ }^{1} \mathrm{H}$ NMR spec-

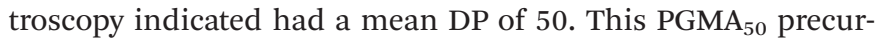
sor was subsequently chain-extended via RAFT aqueous emulsion polymerization of MMA. A series of $\mathrm{PGMA}_{50}-\mathrm{PMMA}_{x}$ nanoparticles were obtained by systematically varying the target DP of the PMMA core-forming block (Scheme 1). High MMA conversions were achieved within $3 \mathrm{~h}$ at $70{ }^{\circ} \mathrm{C}$ for all syntheses (Table 1). DMF GPC analysis indicated relatively high blocking efficiencies and unimodal molecular weight distributions in each case (Fig. 1). Increasing the target PMMA DP led to progressively higher $M_{\mathrm{n}}$ values, albeit with a gradual increase in dispersity (from $M_{\mathrm{w}} / M_{\mathrm{n}}=1.17$ for $\mathrm{PGMA}_{50}-\mathrm{PMMA}_{20}$ up to $M_{\mathrm{w}} / M_{\mathrm{n}}=1.37$ for $\mathrm{PGMA}_{50}-\mathrm{PMMA}_{130}$ ). Similar observations have been reported for various other PISA formulations in the literature. ${ }^{21,29,41}$

TEM studies confirmed that kinetically-trapped spherical nanoparticles of increasing size were obtained when systematically varying the DP of the core-forming PMMA block $(x)$ from 20 to 130 (Fig. 2). Furthermore, dynamic light scattering (DLS) studies revealed a systematic increase in the hydrodynamic $z$-average diameter while DLS polydispersities remained reasonably low up to $x=100$, signifying relatively narrow par-

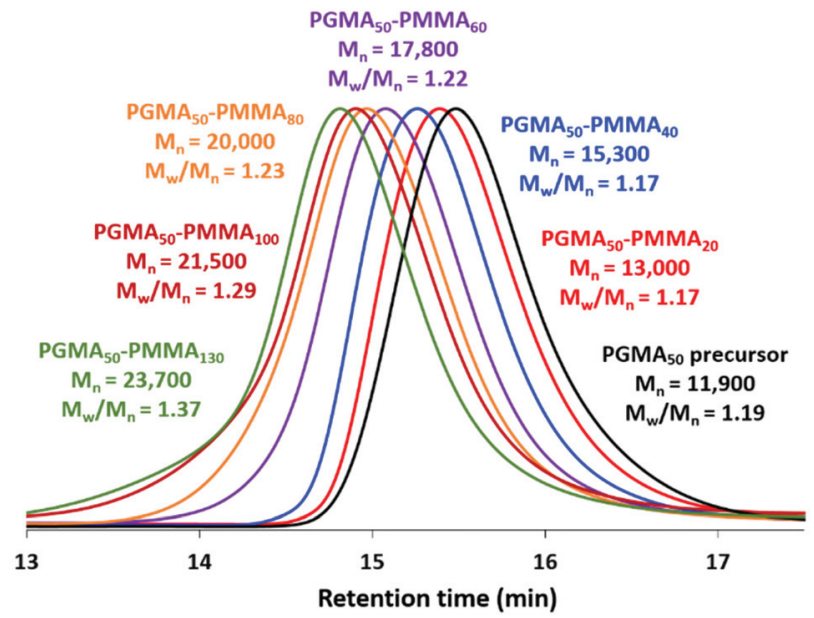

Fig. 1 DMF GPC curves recorded for the $P G M A_{50}$ precursor and a series of PGMA ${ }_{50}-\mathrm{PMMA}_{x}$ nanoparticles for which the target PMMA DP $(x)$ is $20,40,60,80,100$ or 130 (see Table 1 for further details).

ticle size distributions (see Table 1 and Fig. 2). However, a substantial increase in both the apparent $z$-average diameter and DLS polydispersity was observed when targeting $x=130$. Moreover, the TEM image recorded for this PISA synthesis indicates aggregates or clusters of nanoparticles on the grid, suggesting colloidal instability. Various PISA syntheses were conducted targeting $x>100$ and similar results were invariably obtained (data not shown). This was an unexpected limitation, not least because we had previously reported that non-ionic dithiobenzoate-based PGMA precursors with similar (or lower) DPs were effective when performing RAFT aqueous emulsion polymerization syntheses with more hydrophobic methacrylic monomers. For example, Akpinar and co-workers ${ }^{33}$ were able to prepare PGMA $_{28}-$ PTFEMA $_{500}$ and PGMA $_{43}-$ PTFEMA $_{1000}$ spherical nanoparticles with no loss in colloidal stability. Similar results were also obtained by Jesson and co-workers when preparing PGMA $_{39}$-PIPGMA 1000 spheres ${ }^{34}$ and by Cunningham et al. when preparing $\mathrm{PGMA}_{51}-\mathrm{PBzMA}_{1000}$ spheres. $^{32}$

Thus, at first sight, this unforeseen limitation appeared more likely to be associated with the choice of PMMA as the core-forming block, rather than the use of PGMA as a nonionic stabilizer block. A few additional experiments were conducted using a longer PGMA ${ }_{101}$ block as a steric stabilizer. However, nanoparticle aggregation was still observed when tar-

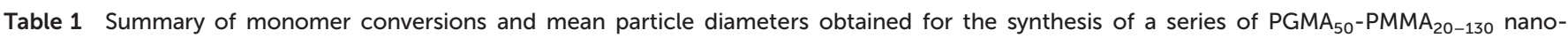
particles via RAFT aqueous emulsion polymerization of MMA at $70{ }^{\circ} \mathrm{C}$ targeting $10 \% \mathrm{w} / \mathrm{w}$ solids

\begin{tabular}{|c|c|c|c|c|c|}
\hline Target PMMA DP & Conversion (\%) & DLS $z$-average diameter (nm) & DLS polydispersity & TEM morphology & SAXS core diameter $(\mathrm{nm})$ \\
\hline 20 & $>99$ & 18 & 0.04 & Spheres & 14 \\
\hline 40 & $>99$ & 20 & 0.04 & Spheres & 15 \\
\hline 60 & $>99$ & 29 & 0.08 & Spheres & 18 \\
\hline 80 & $>99$ & 38 & 0.10 & Spheres & 21 \\
\hline 100 & $>99$ & 66 & 0.12 & Spheres & 24 \\
\hline 130 & 99 & 422 & 0.49 & Spheres & 30 \\
\hline
\end{tabular}


(a)

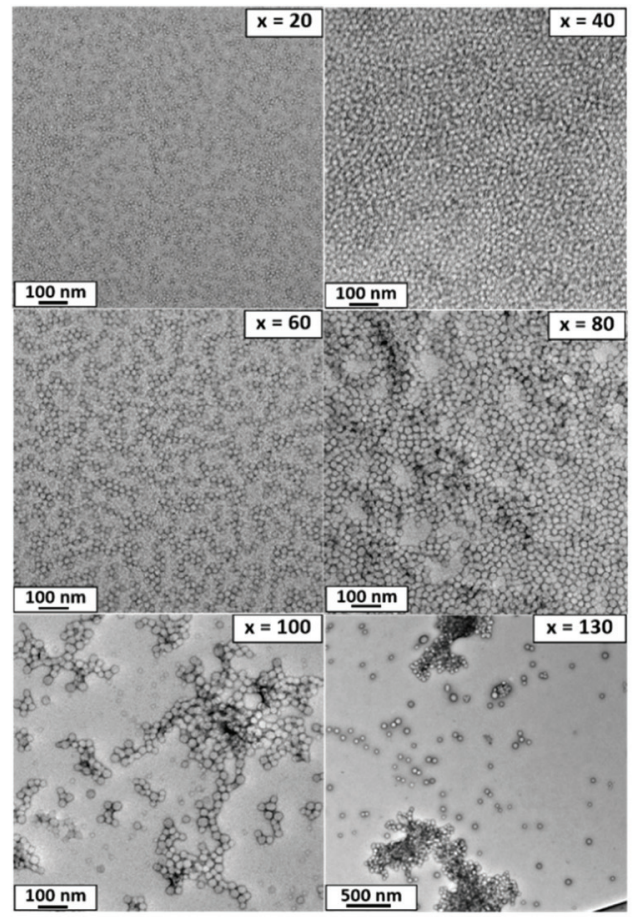

(b)

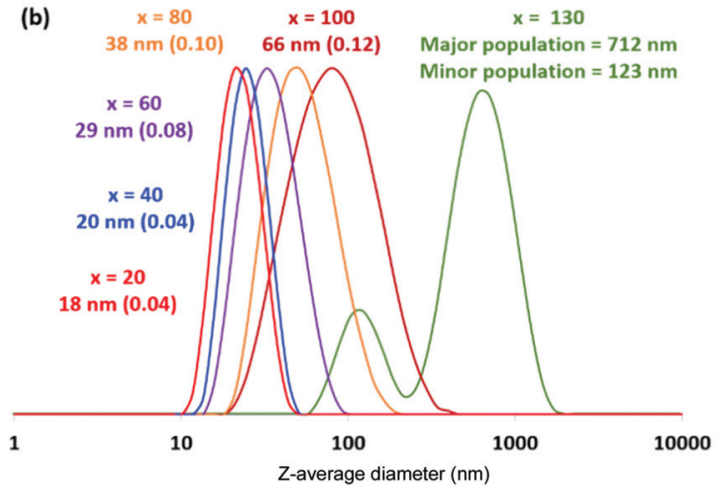

Fig. 2 (a) Representative TEM images and (b) DLS particle size distributions obtained for a series of $P G M A_{50}-P_{M M A}$ nanoparticles prepared by RAFT aqueous emulsion polymerization of MMA where the target PMMA DP $(x)$ is $20,40,60,80,100$ or 130 . DLS indicates a bimodal particle size distribution in the latter case owing to nanoparticle flocculation.

geting PMMA DPs above 100. For example, DLS studies indicated incipient flocculation for $\mathrm{PGMA}_{101}-\mathrm{PMMA}_{200}$ nanoparticles prepared at $70{ }^{\circ} \mathrm{C}$ when targeting $10 \% \mathrm{w} / \mathrm{w}$ solids using the CPDB RAFT agent (data not shown).

SAXS patterns were recorded for $1.0 \% \mathrm{w} / \mathrm{w}$ aqueous dispersions of the $\mathrm{PGMA}_{50}-\mathrm{PMMA}_{20-130}$ nanoparticles. Representative $I(q)$ vs. $q$ plots for six dispersions are shown in Fig. 3. The local minimum observed for each pattern is shifted to lower $q$ as higher PMMA DPs are targeted. This indicates a systematic increase in the nanoparticle core diameter, $d$, according to the well-known relation $q=2 \pi / d .^{48}$ These findings are consistent with the TEM and DLS data discussed above. Moreover, it is well-known that the low $q$ gradient can be used

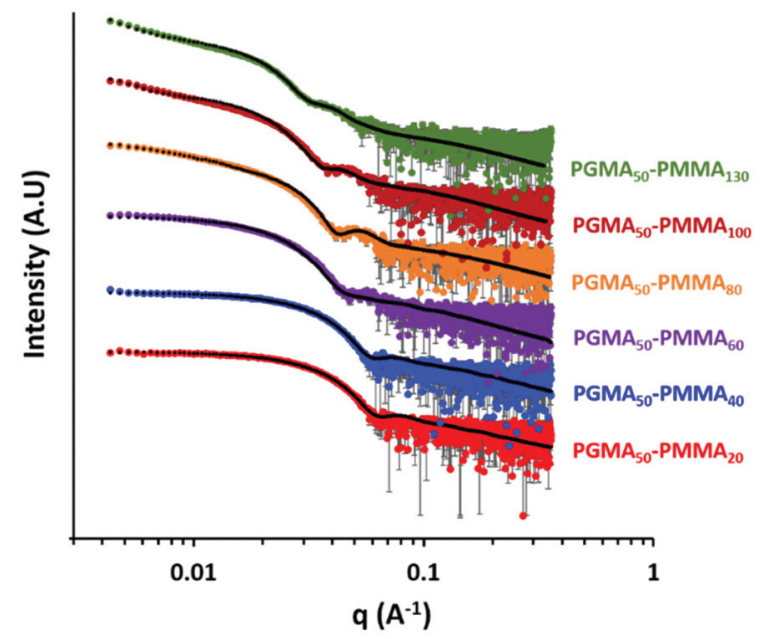

Fig. 3 SAXS patterns recorded for a series of $1.0 \% \mathrm{w} / \mathrm{w}$ aqueous dispersions of $P G M A_{50}-P_{M M A}$ nanoparticles for which the target PMMA DP has been systematically varied from 20 to 130 .

to infer the predominant copolymer morphology. ${ }^{49}$ More specifically, a low $q$ gradient of zero indicates a spherical morphology, which is indeed observed when targeting PMMA DPs of between 20 and 80. However, non-zero low $q$ gradients are observed for $\mathrm{PGMA}_{50}-\mathrm{PMMA}_{100}$ and $\mathrm{PGMA}_{50}-\mathrm{PMMA}_{130}$, which suggests incipient nanoparticle aggregation and the formation of mass fractals for these two dispersions. Again, this is consistent with the corresponding TEM and DLS data shown in Fig. 2. Fitting the SAXS patterns using a well-established spherical micelle model ${ }^{50}$ and also a unified fit ${ }^{51-53}$ (to account for nanoparticle aggregation) enables the volumeaverage diameter of the PMMA cores to be determined in each case (Table 1).

Aqueous electrophoresis studies were performed on $\mathrm{PGMA}_{50}-\mathrm{PMMA}_{80}$ nanoparticles prepared using the dithiobenzoate-capped PGMA $_{50}$ precursor (Fig. 4a). These nanoparticles exhibited zeta potentials close to zero (approximately $-3 \mathrm{mV}$ ) across the whole $\mathrm{pH}$ range, which is consistent with the non-ionic nature of this steric stabilizer block. Given the unexpected colloidal stability problems associated with this PISA formulation, an alternative PGMA stabilizer bearing a carboxylic acid end-group ${ }^{54}$ and an anionic poly(methacrylic acid) stabilizer $^{29}$ were also evaluated for the RAFT aqueous emulsion polymerization of MMA (see Scheme 2). A trithiocarbonatebased RAFT agent, PETTC, was used to prepare a carboxylic acid-capped $\mathrm{PGMA}_{54}$ precursor, which was then chainextended via RAFT aqueous emulsion polymerization of MMA at $\mathrm{pH} 7$ to produce either HOOC-PGMA ${ }_{54}-\mathrm{PMMA}_{80}$ or HOOC-PGMA ${ }_{54}-\mathrm{PMMA}_{150}$ spherical nanoparticles (Scheme 2a). The associated DLS, TEM and GPC data for these two dispersions are summarized in Fig. S1. $\dagger$

The anionic charge conferred by the terminal ionized carboxylic group led to significant anionic character under the PISA synthesis conditions ( $\mathrm{pH} 7$ ) as judged by aqueous electrophoresis studies (see Fig. 4). More specifically, the nano- 


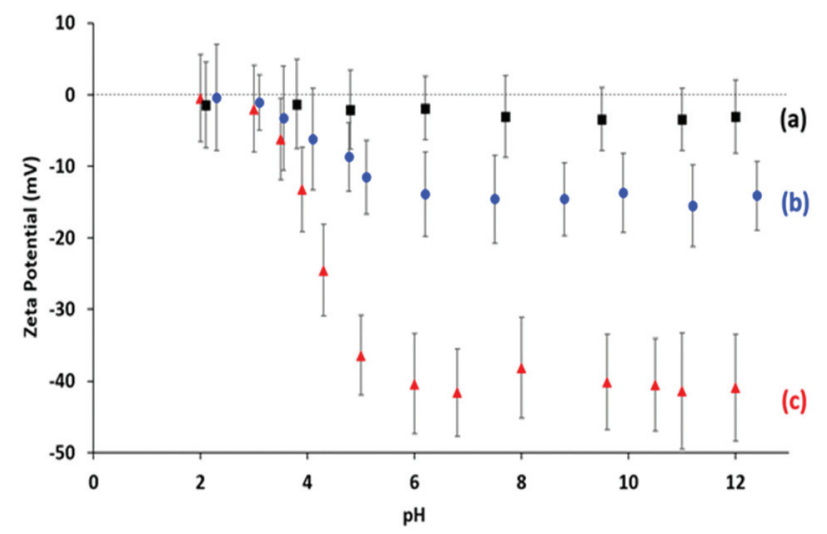

Fig. 4 Zeta potential vs. pH curves obtained for dilute aqueous dispersions of: (a) $\mathrm{PGMA}_{50}-\mathrm{PMMA}_{80}$ spheres prepared using the non-ionic dithiobenzoate-based $\mathrm{PGMA}_{50}$ precursor shown in Scheme 1; (b) HOOC-PGMA ${ }_{54}-\mathrm{PMMA}_{80}$ spheres prepared using the carboxylic acidfunctionalized trithiocarbonate-based $\mathrm{PGMA}_{54}$ precursor shown in Scheme 2a; (c) $\mathrm{PMAA}_{56}-\mathrm{PMMA}_{100}$ spheres prepared using the anionic PMAA precursor shown in Scheme $2 b$.

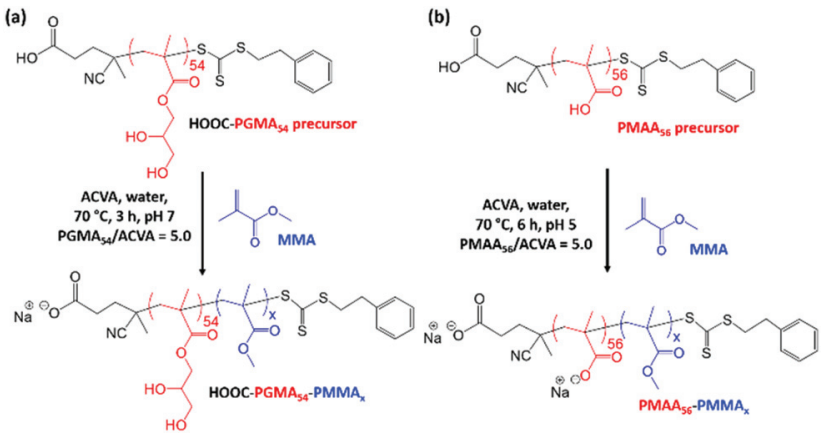

Scheme 2 (a) Synthesis of HOOC-PGMA $54-\mathrm{PMMA}_{x}$ diblock copolymer nanoparticles by RAFT aqueous emulsion polymerization of methyl methacrylate using a trithiocarbonate-based HOOC-PGMA ${ }_{54}$ precursor at $70{ }^{\circ} \mathrm{C}$ and targeting $x=80$ or 150 at $\mathrm{pH}$ 7. (b) Synthesis of $\mathrm{PMAA}_{56^{-}}$ $\mathrm{PMMA}_{x}$ diblock copolymer nanoparticles by RAFT aqueous emulsion polymerization of methyl methacrylate at $70{ }^{\circ} \mathrm{C}$ targeting $x=50$ to 2000 at $\mathrm{pH} 5$.

particles become progressively more anionic between $\mathrm{pH} 2$ and 6 , before a maximum zeta potential of approximately $-14 \mathrm{mV}$ is observed at or above $\mathrm{pH}$ 6. DLS studies confirmed the formation of relatively small nanoparticles with a $z$-average diameter of $26 \mathrm{~nm}$ when targeting a PMMA DP of 80, which indicated good colloidal stability in this case (Fig. S1 $\dagger$ ). However, such anionic character was not sufficient to allow the PISA synthesis of colloidally stable spherical nanoparticles when targeting a PMMA DP of 150. In this case, DLS and TEM studies indicated extensive nanoparticle aggregation similar to that observed for the non-ionic $\mathrm{PGMA}_{50}-\mathrm{PMMA}_{130}$ nanoparticles.

Accordingly, a poly(methacrylic acid) (PMAA) precursor was evaluated for the RAFT aqueous emulsion polymerization of MMA. $^{29}$ A series of PMAA $_{56}-$ PMMA $_{x}$ nanoparticles was prepared using this polyelectrolytic steric stabilizer by systematic variation of the target PMMA DP from 50 to 2000 (see Scheme 2b). All syntheses were performed at $\mathrm{pH} 5$ targeting $20 \% \mathrm{w} / \mathrm{w}$ solids, as reported by Cockram and co-workers for aqueous PISA syntheses using a PMAA steric stabilizer. ${ }^{40}{ }^{1} \mathrm{H}$ NMR spectroscopy studies confirmed that relatively high conversions (94-99\%) were obtained in each case, with a modest reduction in the final conversion being observed when targeting DPs above 500 (Table 2). Mean hydrodynamic diameters determined by DLS are summarized in Table 2 and the relationship between DLS diameter and the PMMA DP is shown in Fig. 5. As expected, the particle size increases monotonically as the target DP is increased from 50 to 2000. Indeed, an approximate linear relationship is observed between DP 50 (29 nm) and DP 500 (73 nm). Above DP 500, the particle size continues to increase up to DP 2000, albeit more slowly. TEM images for selected $\mathrm{PMAA}_{56}-\mathrm{PMMA}_{x}$ nanoparticles are shown in Fig. 6 when targeting $x=50$ to 2000. As expected, a kinetically-trapped spherical morphology was obtained in each case.

Selected $\mathrm{PMAA}_{56}-\mathrm{PMMA}_{x}$ diblock copolymers were methylated to convert such copolymers into the corresponding $\mathrm{PMMA}_{56+x}$ homopolymers for THF GPC analysis using PMMA calibration standards (see Fig. 7). In each case, unimodal MWDs and high blocking efficiencies were observed and targeting higher PMMA DPs led to the expected monotonic increase in the GPC $M_{\mathrm{n}}$. Notably, no systematic GPC error was incurred for this particular data set and the $M_{\mathrm{n}}$ values were reasonably close to the expected theoretical values. However, dispersities were relatively high $\left(M_{\mathrm{w}} / M_{\mathrm{n}}=1.51-1.76\right)$. Similar GPC data were reported by Chaduc and co-workers for the RAFT aqueous emulsion polymerization of MMA using a PMAA precursor at $\mathrm{pH} \mathrm{3.5.} .^{29}$ Clearly, this aqueous PISA formulation does not suffer from colloidal instability problems when targeting relatively high PMMA DPs. This is perhaps not surprising, because aqueous electrophoresis studies of $\mathrm{PMAA}_{56}{ }^{-}$ $\mathrm{PMMA}_{100}$ nanoparticles (Fig. 4c) indicated highly negative zeta potentials (approximately $-40 \mathrm{mV}$ at or above $\mathrm{pH} 5$ ) owing to the strongly anionic nature of the ionized PMAA $_{56}$ chains. Similar results were obtained when employing a cationic steric

Table 2 Summary of monomer conversions and $z$-average diameters obtained for a series of PMAA ${ }_{56}-\mathrm{PMMA}_{50-2000}$ nanoparticles prepared via RAFT aqueous emulsion polymerization of MMA at $70{ }^{\circ} \mathrm{C}$ when targeting $20 \% \mathrm{w} / \mathrm{w}$ solids at $\mathrm{pH} 5$

\begin{tabular}{llllll}
\hline $\begin{array}{l}\text { Target } \\
\text { PMMA }\end{array}$ & $\begin{array}{l}\text { Conversion } \\
\text { DP }\end{array}$ & $\begin{array}{l}\text { Actual } \\
\text { PMMA } \\
\text { DP }\end{array}$ & $\begin{array}{l}\text { DLS } \\
\text { Diameter } \\
(\mathrm{nm})\end{array}$ & $\begin{array}{l}\text { DLS } \\
\text { PDI }\end{array}$ & $\begin{array}{l}\text { TEM } \\
\text { morphology }\end{array}$ \\
\hline 50 & 99 & 50 & 29 & 0.14 & Spheres \\
100 & 99 & 99 & 35 & 0.13 & Spheres \\
200 & 99 & 198 & 42 & 0.16 & Spheres \\
300 & 99 & 297 & 54 & 0.14 & Spheres \\
400 & 99 & 396 & 59 & 0.10 & Spheres \\
500 & 99 & 495 & 73 & 0.11 & Spheres \\
800 & 98 & 784 & 84 & 0.19 & Spheres \\
1000 & 97 & 970 & 92 & 0.17 & Spheres \\
1500 & 94 & 1410 & 94 & 0.20 & Spheres \\
2000 & 95 & 1900 & 99 & 0.24 & Spheres
\end{tabular}




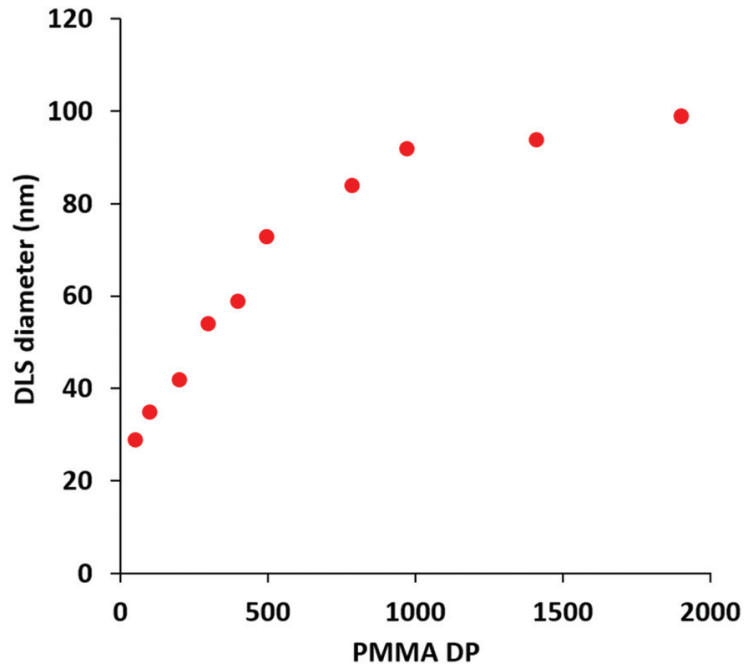

Fig. 5 Variation in $z$-average diameter with PMMA DP ( $x$; corrected for the final monomer conversion) for a series of $\mathrm{PMAA}_{56}-\mathrm{PMMA}_{x}$ diblock copolymer nanoparticles prepared via RAFT aqueous emulsion polymerization of MMA at $70{ }^{\circ} \mathrm{C}$ targeting $20 \% \mathrm{w} / \mathrm{w}$ solids at $\mathrm{pH} 5$.

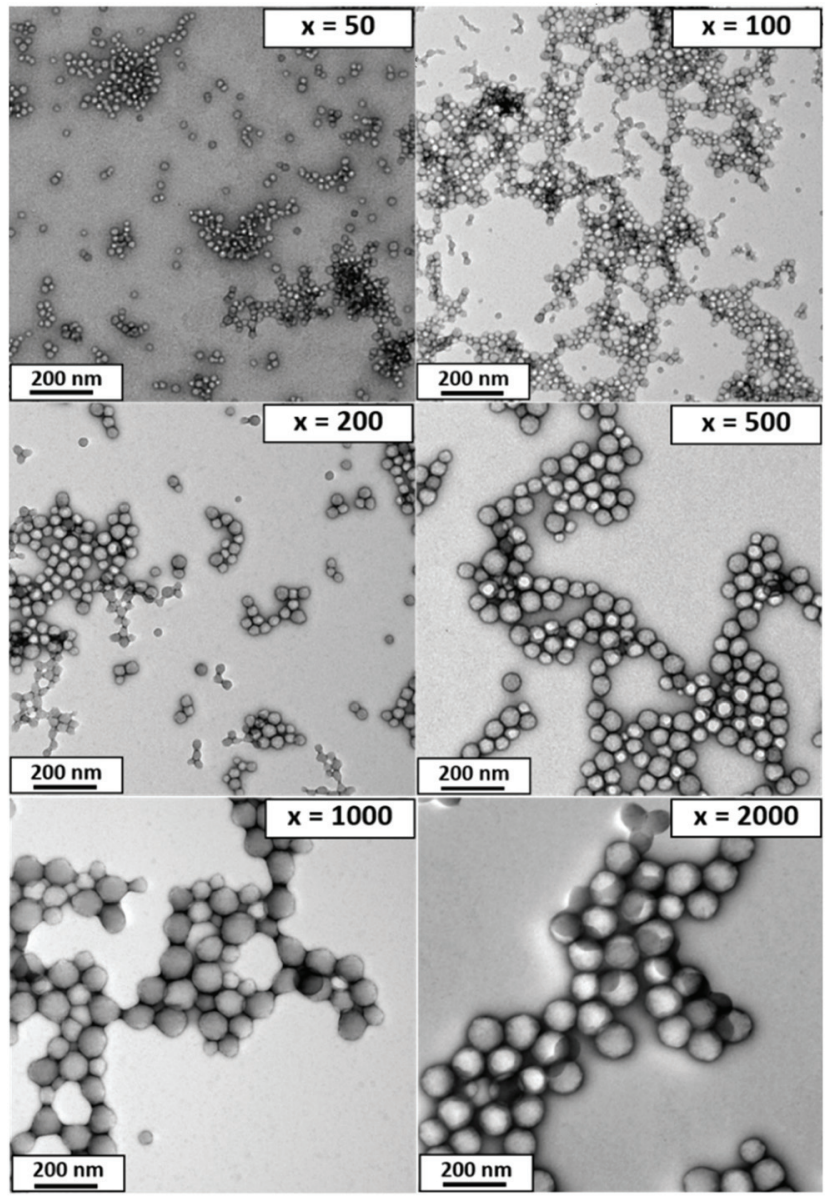

Fig. 6 TEM images recorded for a series of $\mathrm{PMAA}_{56}-\mathrm{PMMA}_{y}$ diblock copolymer nanoparticles prepared by RAFT aqueous emulsion polymerization of MMA when targeting a PMMA DP $(x)$ of $50,100,200,500$, 1000 or 2000 (see Table 2 for further details).

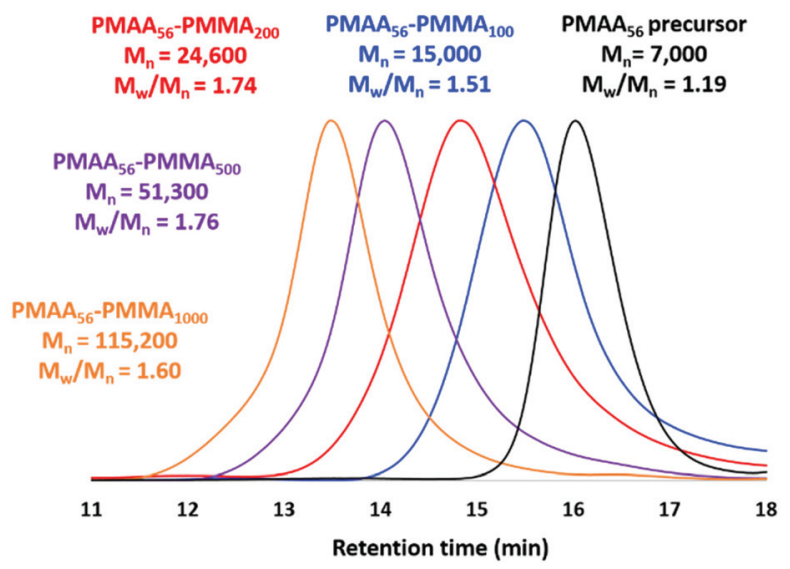

Fig. 7 THF GPC curves recorded for the methylated $P M A A_{56}$ precursor and a series of methylated $\mathrm{PMAA}_{56}-\mathrm{PMMA}_{x}$ diblock copolymer nanoparticles for which the target PMMA DP $(x)$ was $100,200,500$ or 1000.

stabilizer comprising poly(2-(methacryloyloxy)ethyl trimethylammonium chloride) [PMETAC], see the ESI $\uparrow$ for full synthesis details and also Fig. S2. $\dagger$ Thus, if relatively large PMMA-core nanoparticles are required for a given application, it is clear that polyelectrolytic stabilizers offer a decisive advantage over non-ionic stabilizers such as PGMA.

\section{End-group removal from PGMA-PMMA nanoparticles using} visible light irradiation

For many potential applications, it is desirable to remove the RAFT end-groups after the polymerization because these organosulfur groups confer color and malodour. ${ }^{5}$ For soluble copolymers, this is readily achieved using various chemistries. ${ }^{5-57}$ However, there are rather few studies of the removal of RAFT end-groups from diblock copolymer nanoparticles. In 2015, Destarac and co-workers demonstrated that xanthate groups could be efficiently cleaved from aqueous poly( $n$-butyl acrylate) latexes using ozone at ambient temperature. ${ }^{58}$ Subsequently, Jesson $e t ~ a l .{ }^{46}$ reported that dithiobenzoate end-groups can be efficiently removed from PGMA $_{52}-$ PHPMA $_{135}$ (where PHPMA denotes poly(2-hydroxypropyl methacrylate) diblock copolymer worms after treatment with $\mathrm{H}_{2} \mathrm{O}_{2}$ at $70{ }^{\circ} \mathrm{C}$ for $3 \mathrm{~h}$ using a $\mathrm{H}_{2} \mathrm{O}_{2}$ /dithiobenzoate molar ratio of 5.0. However, removal of a trithiocarbonate end-group from essentially the same diblock copolymer proved to be much slower, with around $24 \%$ organosulfur groups remaining after $8 \mathrm{~h}$ under the same reaction conditions. Furthermore, the removal of dithiobenzoate endgroups from $\mathrm{PGMA}_{61}-\mathrm{PBzMA}_{100}$ (where PBzMA denotes poly (benzyl methacrylate) spheres using this $\mathrm{H}_{2} \mathrm{O}_{2}$ protocol was relatively ineffective, with UV GPC analysis indicating that more than $60 \%$ of the original end-groups remained intact after $8 \mathrm{~h}$. This was attributed to the relatively hydrophobic nature of the core-forming PBzMA block, which is likely to impede ingress of the $\mathrm{H}_{2} \mathrm{O}_{2}$ into the nanoparticle cores. More recently, Gibson and co-workers ${ }^{59}$ reported that visible light irradiation (blue LED; $\lambda=405 \mathrm{~nm}$ ) at $50{ }^{\circ} \mathrm{C}$ removed dithiobenzoate end-groups from aqueous dispersions of PNMEP $_{28^{-}}$ 
PLMA $_{87}$ [where PNMEP denotes poly( $N$-(2-methacryloyloxy) ethyl pyrrolidone) and PLMA denotes poly(lauryl methacrylate)] diblock copolymer vesicles. In principle, this approach is attractive because it should not suffer from the retarded diffusion of reagents observed by Jesson and co-workers. ${ }^{46}$ Thus, we decided to study the removal of dithiobenzoate endgroups from $10 \% \mathrm{w} / \mathrm{w}$ aqueous dispersions of $\mathrm{PGMA}_{50^{-}}$ $\mathrm{PMMA}_{80}$ nanoparticles using similar visible light irradiation conditions as those reported by Gibson and co-workers. ${ }^{59}$ Bearing in mind the aqueous solubilities of the respective monomers at room temperature, the hydrophobic character of the core-forming PMMA block is significantly greater than that of PHPMA but rather less than that of either PBzMA or PLMA. Moreover, it is perhaps worth emphasizing that PMMA has a significantly higher glass transition temperature $\left(T_{\mathrm{g}}\right)$ than these three alternative core-forming blocks and it is not obvious whether the glassy nature of the PMMA nanoparticle cores might impede removal of the RAFT end-groups.

In our initial RAFT end-group removal studies, visible light irradiation experiments were conducted at $70{ }^{\circ} \mathrm{C}$. However, only rather slow and incomplete end-group cleavage $(86 \%$ within $24 \mathrm{~h}$; data not shown) was achieved under such conditions for $\mathrm{PGMA}_{50}-\mathrm{PMMA}_{80}$ nanoparticles prepared using CPDB. Fortunately, we found that significantly higher rates of end-group cleavage could be achieved at $80^{\circ} \mathrm{C}$. Accordingly, the kinetics of dithiobenzoate end-group removal by visible light irradiation (blue LED source; $\lambda=405 \mathrm{~nm}$ ) of a $10 \% \mathrm{w} / \mathrm{w}$ aqueous dispersion of $\mathrm{PGMA}_{50}-\mathrm{PMMA}_{80}$ nanoparticles at $80{ }^{\circ} \mathrm{C}$ was monitored by periodic sampling of the reaction mixture followed by DMF GPC analysis using a UV detector set at $309 \mathrm{~nm}$. Unlike visible absorption spectrophotometry, this technique enables the RAFT end-groups that remain attached to the copolymer chains to be distinguished from those that have been cleaved to produce small molecule by-products. ${ }^{46}$ Representative UV GPC curves are shown in Fig. 8a and the fraction of remaining dithiobenzoate end-groups is plotted against time in Fig. 8b. Initially, relatively rapid cleavage occurs, with $87 \%$ of the original end-groups being removed within $12 \mathrm{~h}$ at $80^{\circ} \mathrm{C}$. After continuous irradiation for $24 \mathrm{~h}$, $94 \%$ end-group removal can be achieved and the initial pink copolymer dispersion is converted into a colorless dispersion (see inset digital photographs). As a comparison, $\mathrm{H}_{2} \mathrm{O}_{2}$ was employed for oxidative end-group removal under the same conditions, as previously reported. ${ }^{46}$ However, this only led to $24 \%$ end-group removal within $12 \mathrm{~h}$ and $58 \%$ after $24 \mathrm{~h}$ (Fig. 8b and S3†). This is presumably because this watersoluble reagent cannot readily diffuse into the glassy hydrophobic PMMA cores. The extent of end-group removal was also monitored for the $\mathrm{PGMA}_{50}-\mathrm{PMMA}_{80}$ nanoparticles at $80{ }^{\circ} \mathrm{C}$ in the absence of either visible light irradiation or $\mathrm{H}_{2} \mathrm{O}_{2}$. For this control experiment, UV GPC studies (Fig. S3†) indicated that $92 \%$ end-groups remained intact after $24 \mathrm{~h}$, suggesting minimal thermally-induced hydrolysis.

Precisely the same protocol was adopted when studying trithiocarbonate end-group removal from a $10 \% \mathrm{w} / \mathrm{w}$ (aqueous dispersion of HOOC-PGMA 54 -PMMA 80 nanoparticles. The GPC
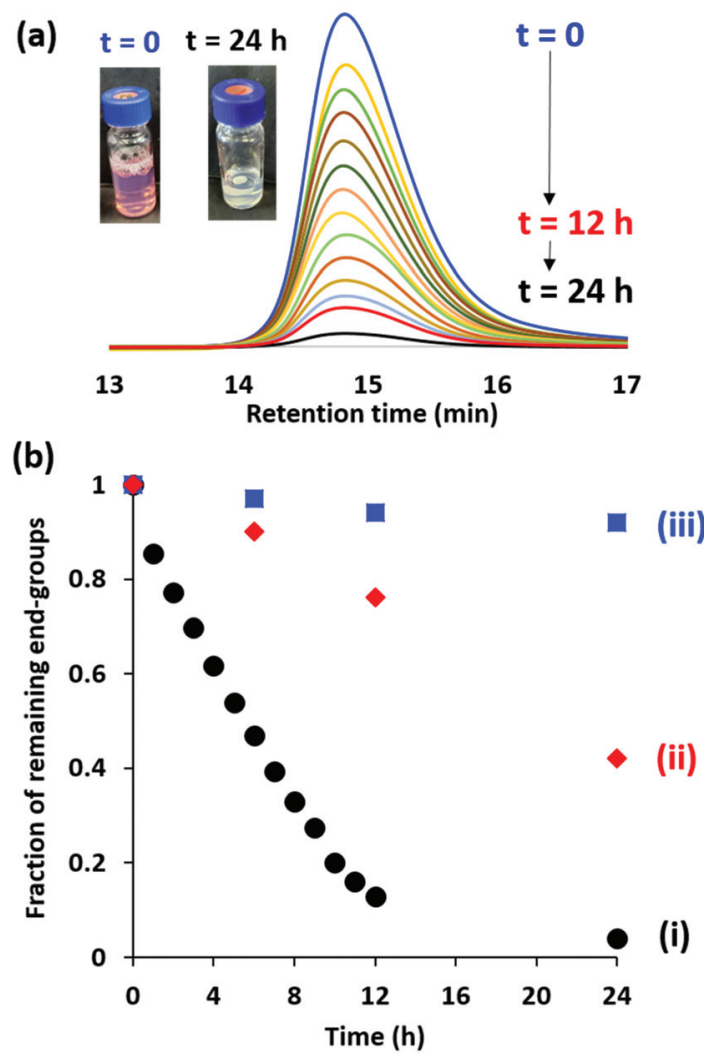

Fig. 8 (a) Representative UV GPC curves ( $\lambda=309 \mathrm{~nm}$ ) recorded during kinetic studies of the cleavage of dithiobenzoate end-groups for a $10 \%$ $\mathrm{w} / \mathrm{w}$ aqueous dispersion of $\mathrm{PGMA}_{50}-\mathrm{PMMA}_{80}$ spherical nanoparticles at $80^{\circ} \mathrm{C}$. (b) Fraction of remaining dithiobenzoate RAFT end-groups over time determined by UV GPC analysis when a $10 \% \mathrm{w} / \mathrm{w}$ aqueous dispersion of $P G M A_{50}-P_{M M A_{80}}$ spherical nanoparticles at $80{ }^{\circ} \mathrm{C}$ is exposed to: (i) continuous visible light irradiation $\left(\lambda=405 \mathrm{~nm}\right.$ ), (ii) $\mathrm{H}_{2} \mathrm{O}_{2}$ (using a $\mathrm{H}_{2} \mathrm{O}_{2}$ /dithiobenzoate molar ratio of 5.0) and (iii) neither visible light nor $\mathrm{H}_{2} \mathrm{O}_{2}$ (control).

curves and kinetics are summarized in Fig. S4. $\dagger$ Cleavage of trithiocarbonate end-groups was achieved, albeit at a somewhat slower rate than that found for the dithiobenzoate endgroups. More specifically, $72 \%$ of the original trithiocarbonate groups were cleaved within $12 \mathrm{~h}$ at $80{ }^{\circ} \mathrm{C}$ with $87 \%$ being removed after $24 \mathrm{~h}$. As a control experiment, the trithiocarbonate-capped $\mathrm{HOOC}_{-\mathrm{PGMA}} \mathrm{PMMA}_{80}$ nanoparticles were exposed to $\mathrm{H}_{2} \mathrm{O}_{2}$ at $80{ }^{\circ} \mathrm{C}$ using a $\mathrm{H}_{2} \mathrm{O}_{2}$ /trithiocarbonate molar ratio of 5.0 (see Fig. S4 and S5†). However, UV GPC studies indicated that more than $80 \%$ of the original RAFT end-groups remained intact within $24 \mathrm{~h}$. Similarly, a control experiment conducted in the absence of either $\mathrm{H}_{2} \mathrm{O}_{2}$ or visible light irradiation indicated that $96 \%$ trithiocarbonate end-groups survived intact after $24 \mathrm{~h}$ at $80^{\circ} \mathrm{C}$.

Clearly, visible light irradiation can be a highly effective means of removing trithiocarbonate end-groups as well as dithiobenzoate end-groups. This approach works well for both high $T_{\mathrm{g}}$ core-forming blocks such as PMMA (as demonstrated herein) and low $T_{\mathrm{g}}$ core-forming blocks such as PLMA. ${ }^{59}$ The only disadvantage appears to be the relatively long reaction 
time required at $80{ }^{\circ} \mathrm{C}$ but presumably this could be reduced by increasing the intensity of the visible light source.

\section{Conclusions}

Sterically-stabilized diblock copolymer nanoparticles are prepared by RAFT aqueous emulsion polymerization of MMA using PGMA as a non-ionic steric stabilizer block. For a target PMMA DP of 20 to 100, kinetically-trapped spherical nanoparticles ranging in size from $17 \mathrm{~nm}$ to $31 \mathrm{~nm}$ are obtained. However, highly flocculated spherical nanoparticles are produced when targeting DPs above 100. Similar flocculation problems are encountered when employing a PGMA stabilizer block that possesses a terminal anionic carboxylate group. Moreover, this unexpected limitation does not appear to apply to various other RAFT aqueous emulsion polymerization formulations: coreforming block DPs of up to 1000 can be targeted without any loss of colloidal stability when employing alternative (and more hydrophobic) water-immiscible monomers such as benzyl methacrylate, 2,2,2-trifluoroethyl methacrylate or isopropylideneglycerol monomethacrylate when using a non-ionic PGMA stabilizer block. This perplexing constraint appears to be related to the high $T_{\mathrm{g}}$ of the PMMA block, which exceeds the reaction temperature of $70{ }^{\circ} \mathrm{C}$ used for such PISA syntheses. However, we demonstrate that colloidally stable dispersions can be obtained when targeting PMMA DPs of up to 2000 using a highly anionic PMAA stabilizer block. Finally, visible light irradiation is used to cleave dithiobenzoate end-groups from a $10 \% \mathrm{w} / \mathrm{w}$ aqueous dispersion of $\mathrm{PGMA}_{50}-\mathrm{PMMA}_{80}$ nanoparticles. UV GPC studies indicated $87 \%$ end-group removal from such nanoparticles within $12 \mathrm{~h}$ at $80{ }^{\circ} \mathrm{C}$. In contrast, using excess $\mathrm{H}_{2} \mathrm{O}_{2}$ only led to $24 \%$ end-group removal under the same conditions. This striking difference is attributed to the water-soluble reagent having restricted access to the hydrophobic PMMA nanoparticle cores. Furthermore, the same visible light irradiation protocol can be used to remove trithiocarbonate end-groups from HOOC-PGMA 50 -PMMA 80 nanoparticles.

\section{Conflicts of interest}

There are no conflicts to declare.

\section{Acknowledgements}

S. P. A. acknowledges a four-year EPSRC Established Career Particle Technology Fellowship (EP/R003009). Syngenta is thanked for an EPSRC Industrial CASE studentship for D. H. H. C. and also for permission to publish this work.

\section{References}

1 J. Chiefari, Y. K. B. Chong, F. Ercole, J. Krstina, J. Jeffery, T. P. T. Le, R. T. A. Mayadunne, G. F. Meijs, C. L. Moad,
G. Moad, E. Rizzardo and S. H. Thang, Macromolecules, 1998, 31, 5559-5562.

2 G. Moad, E. Rizzardo and S. H. Thang, Aust. J. Chem., 2006, 59, 669.

3 G. Moad, E. Rizzardo and S. H. Thang, Aust. J. Chem., 2009, 62, 1402-1472.

4 G. Moad, E. Rizzardo and S. H. Thang, Aust. J. Chem., 2012, 65, 985-1076.

5 S. Perrier, Macromolecules, 2017, 50, 7433-7447.

6 D. J. Keddie, G. Moad, E. Rizzardo and S. H. Thang, Macromolecules, 2012, 45, 5321-5342.

7 J. D. Biasutti, T. P. Davis, F. P. Lucien and J. P. A. Heuts, J. Polym. Sci., Part A: Polym. Chem., 2005, 43, 2001-2012.

8 W. Wan and C. Pan, Polym. Chem., 2010, 1, 1475-1484.

9 Y. Li and S. P. Armes, Angew. Chem., Int. Ed., 2010, 49, 4042-4046.

10 L. A. Fielding, M. J. Derry, V. Ladmiral, J. Rosselgong, A. M. Rodrigues, L. P. D. Ratcliffe and S. P. Armes, Chem. Sci., 2013, 4, 2081-2087.

11 X. Zhang, J. Rieger and B. Charleux, Polym. Chem., 2012, 3, 1502-1509.

12 O. J. Deane, O. M. Musa, A. Fernyhough and S. P. Armes, Macromolecules, 2020, 53, 1422-1434.

13 C. J. Ferguson, R. J. Hughes, B. T. T. Pham, B. S. Hawkett, R. G. Gilbert, A. K. Serelis and C. H. Such, Macromolecules, 2002, 35, 9243-9245.

14 C. J. Ferguson, R. J. Hughes, D. Nguyen, B. T. T. Pham, R. G. Gilbert, A. K. Serelis, C. H. Such and B. S. Hawkett, Macromolecules, 2005, 38, 2191-2204.

15 J. Rieger, F. Stoffelbach, C. Bui, D. Alaimo, C. Jérôme and B. Charleux, Macromolecules, 2008, 41, 4065-4068.

16 B. Charleux, G. Delaittre, J. Rieger and F. D'Agosto, Macromolecules, 2012, 45, 6753-6765.

17 S. L. Canning, G. N. Smith and S. P. Armes, Macromolecules, 2016, 49, 1985-2001.

18 X. Zhang, S. Boissé, W. Zhang, P. Beaunier, F. D’Agosto, J. Rieger and B. Charleux, Macromolecules, 2011, 44, 41494158.

19 S. Boissé, J. Rieger, G. Pembouong, P. Beaunier and B. Charleux, J. Polym. Sci., Part A: Polym. Chem., 2011, 49, 3346-3354.

20 W. Zhang, F. D'Agosto, O. Boyron, J. Rieger and B. Charleux, Macromolecules, 2012, 45, 4075-4084.

21 L. Carlsson, A. Fall, I. Chaduc, L. Wågberg, B. Charleux, E. Malmström, F. D'Agosto, M. Lansalot and A. Carlmark, Polym. Chem., 2014, 5, 6076-6086.

22 W. Zhang, B. Charleux and P. Cassagnau, Macromolecules, 2012, 45, 5273-5280.

23 B. T. T. Pham, D. Nguyen, V. T. Huynh, E. H. Pan, B. Shirodkar-Robinson, M. Carey, A. K. Serelis, G. G. Warr, T. Davey, C. H. Such and B. S. Hawkett, Langmuir, 2018, 34, 4255-4263.

24 R. Albigès, P. Klein, S. Roi, F. Stoffelbach, C. Creton, L. Bouteiller and J. Rieger, Polym. Chem., 2017, 8, 4992-4995.

25 N. P. Truong, M. V. Dussert, M. R. Whittaker, J. F. Quinn and T. P. Davis, Polym. Chem., 2015, 6, 3865-3874. 
26 W. Zhao, G. Gody, S. Dong, P. B. Zetterlund and S. Perrier, Polym. Chem., 2014, 5, 6990-7003.

27 I. Chaduc, O. Boyron, B. Charleux, F. D. Agosto and M. Lansalot, Macromolecules, 2013, 46, 6013-6023.

28 J. Rieger, G. Osterwinter, C. Bui and B. Charleux, Macromolecules, 2009, 42, 5518-5525.

29 I. Chaduc, M. Girod, R. Antoine, B. Charleux, F. D’Agosto and M. Lansalot, Macromolecules, 2012, 45, 5881-5893.

30 M. Chenal, C. Véchambre, J. M. Chenal, L. Chazeau, V. Humblot, L. Bouteiller, C. Creton and J. Rieger, Polymer, 2017, 109, 187-196.

31 S. Binauld, L. Delafresnaye, B. Charleux, F. Dagosto and M. Lansalot, Macromolecules, 2014, 47, 3461-3472.

32 V. J. Cunningham, A. M. Alswieleh, K. L. Thompson, M. Williams, G. J. Leggett, S. P. Armes and O. M. Musa, Macromolecules, 2014, 47, 5613-5623.

33 B. Akpinar, L. A. Fielding, V. J. Cunningham, Y. Ning, O. O. Mykhaylyk, P. W. Fowler and S. P. Armes, Macromolecules, 2016, 49, 5160-5171.

34 C. P. Jesson, V. J. Cunningham, M. J. Smallridge and S. P. Armes, Macromolecules, 2018, 51, 3221-3232.

35 E. E. Brotherton, F. L. Hatton, A. A. Cockram, M. J. Derry, A. Czajka, E. J. Cornel, P. D. Topham, O. O. Mykhaylyk and S. P. Armes, J. Am. Chem. Soc., 2019, 141, 13664-13675.

36 F. L. Hatton, J. R. Lovett and S. P. Armes, Polym. Chem., 2017, 8, 4856-4868.

37 J. Tan, D. Liu, C. Huang, X. Li, J. He, Q. Xu and L. Zhang, Macromol. Rapid Commun., 2017, 38, 1-7.

38 F. L. Hatton, A. M. Park, Y. Zhang, G. D. Fuchs, C. K. Ober and S. P. Armes, Polym. Chem., 2019, 10, 194-200.

39 F. L. Hatton, M. J. Derry and S. P. Armes, Polym. Chem., 2020, 11, 6343-6355.

40 A. A. Cockram, T. J. Neal, M. J. Derry, O. O. Mykhaylyk, N. S. J. Williams, M. W. Murray, S. N. Emmett and S. P. Armes, Macromolecules, 2017, 50, 796-802.

41 W. Zhang, F. D'Agosto, P. Y. Dugas, J. Rieger and B. Charleux, Polymer, 2013, 54, 2011-2019.
42 F. L. Hatton, M. Ruda, M. Lansalot, F. D. Agosto, E. Malmstro and A. Carlmark, Biomacromolecules, 2016, 17, 1414-1424.

43 J. Engström, H. Asem, H. Brismar, Y. Zhang, M. Malkoch and E. Malmström, Macromol. Chem. Phys., 2020, 221, 1900443.

44 S. J. Hunter, J. R. Lovett, O. O. Mykhaylyk, E. R. Jones and S. P. Armes, Polym. Chem., 2021, 12, 3629-3639.

45 M. Semsarilar, V. Ladmiral, A. Blanazs and S. P. Armes, Langmuir, 2013, 29, 7416-7424.

46 C. P. Jesson, C. M. Pearce, H. Simon, A. Werner, V. J. Cunningham, J. R. Lovett, M. J. Smallridge, N. J. Warren and S. P. Armes, Macromolecules, 2017, 50, 182-191.

47 J. Ilavsky and P. R. Jemian, J. Appl. Crystallogr., 2009, 42, 347-353.

48 A. Guinier and G. Fournet, Small-Angle Scattering of X-rays, John Wiley \& Sons, New York, 1955.

49 O. Glatter and O. Kratky, Small-angle X-ray Scattering, Academic Press, London, 1982.

50 J. S. Pedersen, J. Appl. Crystallogr., 2000, 33, 637-640.

51 G. Beaucage and D. W. Schaefer, J. Non.-Cryst. Solids, 1994, 172-174, 797-805.

52 G. Beaucage, J. Appl. Crystallogr., 1995, 28, 717-728.

53 G. Beaucage, J. Appl. Crystallogr., 1996, 29, 134-146.

54 J. R. Lovett, N. J. Warren, L. P. D. Ratcliffe, M. K. Kocik and S. P. Armes, Angew. Chem., Int. Ed., 2015, 54, 1279-1283.

55 S. Perrier and P. Takolpuckdee, J. Polym. Sci., Part A: Polym. Chem., 2005, 43, 5347-5393.

56 H. Willcock and R. K. O'Reilly, Polym. Chem., 2010, 1, 149157.

57 B. Quiclet-Sire and S. Z. Zard, Bull. Korean Chem. Soc., 2010, 31, 543-544.

58 D. Matioszek, P. E. Dufils, J. Vinas and M. Destarac, Macromol. Rapid Commun., 2015, 36, 1354-1361.

59 R. R. Gibson, E. J. Cornel, O. M. Musa, A. Fernyhough and S. P. Armes, Polym. Chem., 2020, 11, 1785-1796. 